Egypt. Acad. J. Biolog. Sci., 12(1): 31-35 (2020)

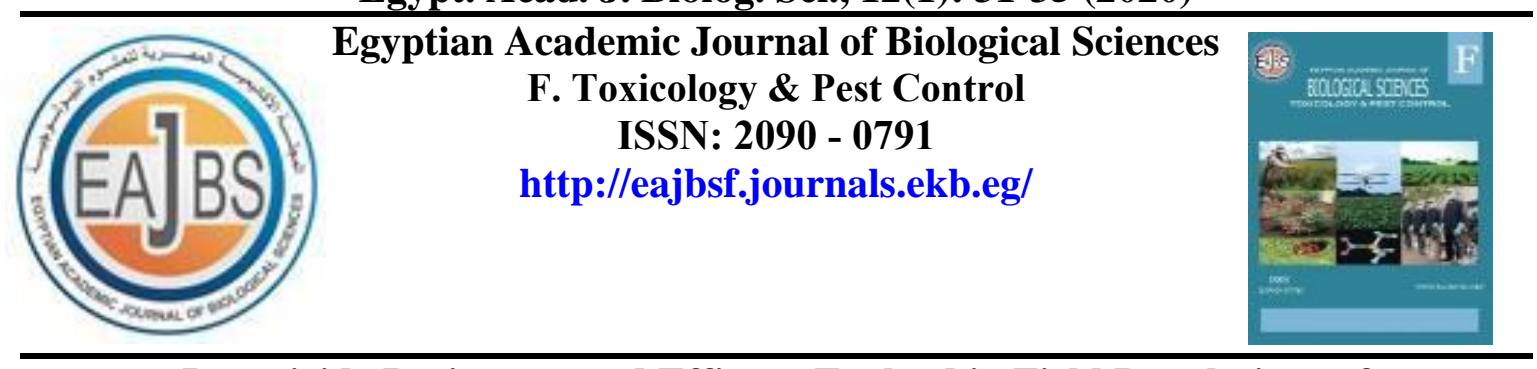

\title{
Insecticide Resistance and Efficacy Evolved in Field Populations of Spodoptera littoralis in Egypt Cotton Season
}

\author{
Mona, K. Elhadek; Sameh. Sh. Hafez and Reham, E. Ali \\ Agriculture Research Center, Central Agricultural Pesticides Laboratory, Giza, Egypt \\ *Email: monahazek@yahoo.com
}

\begin{abstract}
ARTICLE INFO
Article History

Received:9/1/2020

Accepted:12/2/2020

Keywords:

Spodoptera

littoralis,

bioinsecticides,

$I G R, \mathrm{~s}$, and

several

Governorates

ABSTRACT

This study aimed mainly to estimate the resistance of the cotton leafworm Spodoptera littoralis to several bioinsecticides Agerine 6.5\% WP, Protecto $9.4 \%$ WP biotect $9.4 \%$, wp Dipel 2x 6.4\% WP, Dipel Df $5.4 \%$ WG and two other bioinsecticides, Emamectin benzoate (Radical $0.5 \%$ ) EC against Spodoptera littoralis that all field strains the tested bioinsecticides used against cotton leafworm $S$. littoralis were calculated for both susebtable and field strains collected from six governorates namely Sharkia, Dakahlia, Behera, kafr- Elshek, Fayuom and Beni- swef in the cotton season 2019.

The resistance ratio fluctuated from very low resistance to low resistance in some governorates to others except low of governorates RR indicated high resistance.

tested IGR' s used against cotton leafworm S. littoralis were calculated for both susebtable and field strains collected from six governorates namely Sharkia, Dakahlia, Behera, kafr- Elshek, Fayuom, and Beni-Swef in the cotton season 2019. showed no resistance in all tested IGR, s for all Governorates, except some Governorate in some IGR, s
\end{abstract}

INTRODUCTION

The cotton leafworm Spodoptera littoralis (Boisd.) (Lepidoptera: Noctuidae) is a polyphagous insect pest. It is considered to be a major pest of great economic importance in many countries since it attacks several host plants ( 40 families). The damage is mainly due to

The young larvae feed on the foliage, where large numbers of older larvae can defoliate plants.

Cotton leafworm is one of the most economically important insect pests in cotton in Egypt. Due to the repeated application of conventional insecticides over years, resistance in cotton leafworm was developed against many conventional insecticides. Alternatively, bioinsecticides were used to control such insects through the integrated pest management (IPM) programs insecticides still have an important role in controlling such insect-pest as they are considered the principal method for controlling S. littoralis in Egypt and will likely to continue to be used. (Hafez et.al. 2018) Resistance Monitoring in Cotton Leaf worm Spodoptera littoralis to Certain Bioinsecticides during Ten cotton Seasons in Eight Governorates on Egypt.

However, due to concern about the impact of traditional insecticides on both health

Citation: Egypt. Acad. J. Biolog. Sci. (F. Toxicology \& Pest control) Vol. 12(1) pp. 31 - 35 (2020) 
and environment, it has resulted in the search for alternative control measures (Mondal1 and Parween 2001).

Mondal1 and Parween (2001) insect growth regulators and their potential in the management of stored-product insect pests. The use of bio-insecticides and insect growth regulators (IGRs) in insect control is known has shown potentiality against Lepidopterous insects. Farag, (2001) Abdel-Aal, (2003) and Seth et al., (2004).

Aim of this study monitoring of resistance in Bioinsecticides and IGRs insecticides in 2019 cotton season against Spodoptera littoralis in Six Governorates

\section{MATERIALS AND METHODS}

\section{Field Strain:}

six field strains of the cotton leafworm were collected from the cotton field in Egypt from several locations (bini-swef, fayoum. Sharkia, Dakahlia, Kafr- elshakh and Behera) from 2019. After collection, the egg-masses were kept separately in $400 \mathrm{ml}$ jar, covered with muslin held in position by rubber band until the eggs hatched. The jars were provided with castor oil leaves for larval feeding and to provide the required humidity for hatching. All cotton leafworm field strains and laboratory strain were reared at $25 \pm 2 \mathrm{C}^{0}$ and $70 \pm 5 \%$ relative humidity. The larvae were then used for bioassay study.

\section{Insecticides used.}

The use of bio-insecticides and insect growth regulators (IGRs) in insect control is known has shown potentiality against Lepidopterous insects (Table 1). We obtained these insecticides from pesticides company.

Table (1): commercial formulations of the tested insecticides

\begin{tabular}{|c|c|c|c|}
\hline \multicolumn{5}{|c|}{ Bio-insecticides } \\
\hline N0 & Chemical name & Formulation & $\begin{array}{c}\text { Trade name- } \\
\text { conc }\end{array}$ \\
\hline 1 & Bacillus thurigiensis & WP & Dipel 2 x 6.5 \% \\
\hline 2 & Bacillus thurigiensis & WP & Agreen 6.5 \% \\
\hline 3 & Bacillus thurigiensis & WP & Brotecto 9.4 \% \\
\hline 4 & Bacillus thurigiensis & WG & Dipel Df 6.5 \% \\
\hline 5 & Bacillus thurigiensis & WP & Biotect 9.4 \% \\
\hline 6 & Emamectin benzoate & EC & Radical 0.5\% \\
\hline 7 & Spinetoram & EC & Radent 12 \% \\
\hline \multicolumn{4}{|c|}{ Insect Growth Regulators (IGRs) } \\
\hline 1 & Chlorfluazuron & EC & Kabres 5\% \\
\hline 2 & Chlorfluazuron & EC & Toberon 5\% \\
\hline 3 & Flufenoxuron & DC & Kalegron 10 \% \\
\hline 4 & Hexaflumuron & EC & Demeron 10\% \\
\hline 5 & Lufenuron & EC & Match 5\% \\
\hline 6 & Diflbenzuron & SC & Demelen 48\% \\
\hline 7 & Demefron 25 \% & WP & Demefron 25\% \\
\hline 8 & Alsesten & SC & Triflumuron 48\% \\
\hline \multicolumn{4}{|c|}{} \\
\hline
\end{tabular}

\section{Bioassay Tests:}

Six aqueous concentrations for each insecticide formulation were prepared. Fresh castor - bean Ricinus communis leaves were dipped for 15 seconds in each concentration then left for one hour to dry. Then, the $4^{\text {th }}$ instar larvae of each strain were fed on treated 
leaves and kept in plastic for $24 \mathrm{hr}$ in jars and covered with muslin, and then the treated leaves were removed and provided with fresh untreated leaves in clean jars for another three days. A susceptible strain od S. littoralis was obtained from the central Agricultural pesticides Laboratory, Dokki, Egypt, where it has been reared on Fresh castor bean Ricinus communis leaves for several generations without exposure to insecticides. It served as a base line reference strain for the comparisons between the studied strains. Three replicates of ten larvae were tested for each concentration. Mortality percentages were recorded after 5 days from larvae transfer onto untreated leaves and mortality percentage was corrected according to Abbot, 1925. To estimate the $\mathrm{LC}_{50}$ values, the corrected mortality percentages were subjected to probit analysis according to the method of Finney (1971). The level of resistance in the field strains was calculated as the resistance ratio (RR) compared with the susceptible strain.

\section{Resistance Ratio $(\mathrm{RR})=\mathrm{LC}_{50}$ of field strain $/ \mathrm{LC}_{\mathbf{5 0}}$ of susceptible strain}

\section{RESULTS AND DISCUSSION}

\section{LC $_{50}$, Slope and Resistance Ratio of Certain Bioinsecticides:}

Data in Table (2) showed the LC50, slope and resistance ratio (RR) for the tested bioinsecticides used against cotton leafworm $S$. littoralis collected from six governorates namely Sharkia, Dakahlia, Behera, kafr- Elshek, Fayuom and Bin- swif in the cotton season 2019.

The resistance ratio fluctuated from very low resistance to low resistance in some Governorates to others except low of governorates RR indicated high resistance.

It is clear from the results Biotect had higher-level resistance in Behera Governorate RR was (10.78-fold) also in radical bioinsecticide in Kafr -Elshek Governorate data showed a very high level of resistance RR was 23.6-fold in Fayoum Governorate. also in Dipel2X showed a high level of resistance RR,s it was 9.04 fold, but in radical bioinsecticide showed a moderate level of resistance RR was 5.66 fold.

On the other hand, all bioinsecticides were highly effective in all Governorates The LC50 values were $(0.015,61.56,23.0,53,23.7,2.93,0.014$ and 2.61) ppm in radical, Agreen, Dipel 2X, Dipel Df, Brotecto, Radecal, and Biotect respectively, in Sharkia governorate but in Dakahlia Governorate LC50 were (20.0, 36, 16.94, 18.25, 26.40, 14.99, 2.83 and 1.30) ppm for bioinsecticides Agreen, Dipel 2X, Dipel Df, Brotecto, Radecal, and Biotect respectively. also in Behera Governorate $\mathrm{LC}_{50}$ were $(0.62,74.53,92.16$, $43.79,39.98,0.006$ and 161.7) ppm respectively, in bioinsecticides. On the other hand LC $_{50}$ in Kaf-Elshek were $(0.73,240.45,158.82,433.35,156.24,0.33$ and 41.11) ppm respectively. Finally, in upper Egypt Governorates also the bioinsecticides showed a high level of effective against $S$. littoralis, $\mathrm{LC}_{50}$ in Fayuom Governorate were $(0.065,98.25,153.22,39.6,3.74,0.068$ and 0.00007$) \mathrm{ppm}$ for radical, green, dipel 2x, dipel df, brotecto and biotect respectively.

Also in Beni- swif Governorate LC50 were $(0.001,28.64,7.05,30.75,1.10,0.0014$ and 1.71) ppm respectively.Finally, it is hoped that the present result will aid in better control of cotton leafworm $S$. littoralis.

Singab et. al. (2014) studied the resistance of the cotton leafworm S. littoralis to several bioinsecticides (Spnitor. Protecto, Dipel DF, Dipel 2x, Agrine and Radical) throughout determining the resistance ratio in four Governorates.

Hafez et.al. (2018) determined the Resistance ratio of six bioinsecticides in eight strains of Spodoptera littoralis which collected from bini-swef, fayoum. Sharkia, Dakahlia. Menofia, Gharbia, Kafr- elshakh and Behera from 2008 to 2017 cotton seasons. 
The results indicate that resistance ratios RR fluctuated from one year to another and from Governorate to another. During ten cotton seasons, the tested Bacillus thuringiensis Agerine 6.5\% WP, Protecto 9.4 \%WP, Dipel 2x 6.4\% WP, Dipel Df 5.4\% WG and two other bioinsecticides, Spinosad (Spintor $24 \%$ SC) and Emamectinbenzoate (Radical 0.5 $\%$ ) in all field strains were very highly effective spintor and Radical followed by Dipel $2 \mathrm{X}$ and Dipel Df followed by protect and in case last one was Agrein.

Table 2: LC50, Slope and resistance ratio of certain bioinsecticides from six Governorates against S.littoralis

\begin{tabular}{|c|c|c|c|c|c|c|c|c|c|c|c|c|c|c|c|c|c|c|c|c|}
\hline \multirow[b]{2}{*}{ Compounds } & \multicolumn{2}{|c|}{ Susceptible } & \multicolumn{3}{|c|}{ Sharkia } & \multicolumn{3}{|c|}{ Dakahlia } & \multicolumn{3}{|c|}{ Behera } & \multicolumn{3}{|c|}{ Kafr-Elshek } & \multicolumn{3}{|c|}{ Fayuom } & \multicolumn{3}{|c|}{ Bini-sweif } \\
\hline & $\begin{array}{l}\mathbf{L C}_{50} \\
\mathrm{ppm}\end{array}$ & slope & $\begin{array}{l}L_{5} C_{50} \\
\text { ppm }\end{array}$ & slope & RR & $\begin{array}{l}L_{50} \\
\text { ppm }\end{array}$ & slope & RR & $\begin{array}{l}\mathrm{LC}_{50} \\
\mathrm{ppm}\end{array}$ & slope & RR & $\begin{array}{l}L^{L} C_{50} \\
\text { ppm }\end{array}$ & slope & RR & $\begin{array}{l}L_{50} \\
\text { ppm }\end{array}$ & slope & RR & $\begin{array}{l}L^{2} C_{50} \\
\text { ppm }\end{array}$ & slope & RR \\
\hline Radeiant & 2.83 & 1.91 & 0.015 & 0.81 & 0.005 & 20.36 & 0.91 & 3.46 & 0.02 & 1.54 & \begin{tabular}{|l|}
0.007 \\
\end{tabular} & 0.73 & 0.21 & 0.25 & 0.065 & 0.86 & 0.02 & \begin{tabular}{|l|l|}
0.001 \\
\end{tabular} & 0.37 & 0.0006 \\
\hline Agrien & 20.3 & 0.99 & 61.56 & 0.97 & 3.03 & 16.94 & 0.84 & 1.40 & 74.53 & 0.65 & 1.36 & 240.45 & 0.16 & 4.41 & 98.25 & 0.48 & 4.82 & \begin{tabular}{|l|l|}
28.64 \\
\end{tabular} & 1.00 & 1.4 \\
\hline Daipel2X & 18.94 & 1.64 & 23.53 & 0.78 & 1.24 & 18.25 & 0.88 & 1.95 & 92.16 & 1.43 & 0.77 & 158.82 & 0.17 & 1.34 & 153.22 & 0.81 & 9.04 & 7.05 & 0.83 & 0.41 \\
\hline Daipeldf & 20.22 & 1.96 & 23.7 & 0.78 & 1.17 & 26.40 & 0.73 & 0.04 & 43.79 & 1.01 & 0.14 & 433.35 & 0.25 & 1.41 & 39.6 & 0.74 & 2.16 & 30.75 & 0.91 & 1.67 \\
\hline Brotecto & 26.40 & 1.64 & 2.39 & 0.76 & 0.09 & 14.99 & 0.61 & 0.26 & 39.98 & 1.21 & 0.20 & 156.92 & 0.24 & 0.79 & 3.74 & 0.92 & 0.14 & \begin{tabular}{|l|}
1.10 \\
\end{tabular} & 0.65 & 0.041 \\
\hline Radecal & 1.30 & 1.66 & 0.014 & 0.83 & 0.01 & 2.83 & 1.01 & 0.013 & 0.006 & 1.37 & 0.48 & 0.33 & 0.24 & 26.6 & 0.068 & 0.59 & 5.66 & 0.0014 & 0.75 & 0.116 \\
\hline Biotect & 20.37 & 1.23 & 2.61 & 0.73 & 0.12 & 1.30 & 0.68 & 0.067 & 1.72 & 1.08 & 10.78 & 41.11 & 0.15 & 2.74 & 0.00007 & 0.1 & $0.00004 \mathrm{t}$ & 1.71 & 0.55 & .0001 \\
\hline
\end{tabular}

\section{$\mathbf{L C}_{50}$, Slope and Resistance Ratio of Certain Igrs:}

Data in Table (3) showed $\mathrm{LC}_{50}$, slope and resistance ratio (RR) for the tested IGR,s used against $S$. littoralis were calculated for both susebtable and field strains collected from six governorates namely Sharkia, Dakahlia, Behera, kafr- Elshek, Fayuom and Binswif in the cotton season 2019. Data in Table (3) showed no resistance in all tested IGR,s for all Governorates, except in Dakahlia Governorate for Demelen IGR,s RR was very high-level RR was 60.8 fold and in Demefron RR was 40.00 fold. Also, in Kafr-Elshek Governorate the IGR Demelen and Alsysten showed very high resistance and RR values were 7.13 and 8.88-fold respectively. On the other hand, also in bini- swief Governorate RR was very high in toberon and Alsysten RR was 8.8 fold respectively. On the other hand, all IGR,S showed high effective in all Governorates against S. littoralis. LC 50 values in Sharkia Governorate were $(2.91,0.17,0.28,0.10,1.49,0.69,0.03$ and 1.52) ppm in Demelen, Toberon, Demeron, Kabres,Kalegron, Alsysten, Match, and Demefron respectively.also in Dakahlia Governorate $\mathrm{LC}_{50}$ very low $\mathrm{RR}$ were $(2.075,35.68,1.13,3.92,0.093$, and 0.0088 ) ppm respectively in IGR,s Toberon, Demeron, Kabres,Kalegron, Alsysten, Match. In Behera Governorate LC 50 flctuated from 0.69 to $8.73 \mathrm{ppm}$ for all IGR, S. on the other hand in Kar- ElShek Governorate LC 50 fluctuated from (0.77 to 19.61) ppm.

Finally, in Fayuom and Bin-Swif LC50 was very low in all IGRs.Helaly et.al. (2015) studied as a selective biological insecticide, spinosad which has been widely used for the control of pests including S. littoralis. It was studied very well in the laboratory last decade but there are a lake in knowledge in both field evaluations, lethal and sublethal effects to obtain a complete analysis of Spinosad impact. This study attempts to evaluate the lethal and sublethal effects of spinosad on this pest by recording and analyzing various toxicological and physiological parameters. The toxicity of spinosad against $S$. littoralis was determined under Egyptian field conditions on Tomato plants in Fayoum Governorate in the period extended from June to July of 2014 conditions by oral exposure of late second instar larvae to the compounds. The LC50 values of spinosad to S. littoralis tested at 24, 48, 72, 96,120, 144 and $168 \mathrm{~h}$ after treatment were 37.580, $19.050,9.028,7.019,5.0182,4.0181$ and $2.0109 \mathrm{mg} \mathrm{x} \mathrm{kg}(-1)$, respectively. Spinosad at sublethal concentrations significantly extended the developmental period of survivor larvae, and reduced larval wet weight. 
The present study indicates high efficacy of the tested IGRs and Bio-insecticides to be used as an effective alternative method of $S$. littoralis control where insecticide resistance has developed for other conventional insecticides.

Table 3: LC50, Slope and resistance ratio of certain IGRs from six Governorates against S.littoralis

\begin{tabular}{|c|c|c|c|c|c|c|c|c|c|c|c|c|c|c|c|c|c|c|c|c|}
\hline \multirow[b]{2}{*}{ Compounds } & \multicolumn{2}{|c|}{ Susceptible } & \multicolumn{3}{|c|}{ Sharkia } & \multicolumn{3}{|c|}{ Dakahlia } & \multicolumn{3}{|c|}{ Behera } & \multicolumn{3}{|c|}{ KafElshek } & \multicolumn{3}{|c|}{ Fayoum } & \multicolumn{3}{|c|}{ Bin-swief } \\
\hline & $\mathrm{LC}_{50}$ & slope & $L_{50}$ & slope & RR & $\mathrm{LC}_{50}$ & slope & RR & $L C_{50}$ & slope & RR & $\mathrm{LC}_{50}$ & slope & RR & $L C_{50}$ & slope & RR & $L_{50}$ & slope & RR \\
\hline Demelen & 1.16 & 1.28 & 2.91 & 1.21 & 2.5 & 70.56 & 0.91 & 60.8 & 2.74 & 0.51 & 2.36 & 8.28 & 0.78 & 7.13 & 2.09 & 0.89 & 1.80 & 5.38 & 1.01 & 4.63 \\
\hline Tobron & 0.95 & 1.49 & 0.17 & 0.79 & 0.17 & 23.75 & 0.84 & 1.40 & 1.57 & 0.75 & 1.65 & 1.24 & 0.612 & 1.3 & 0.56 & 0.81 & 0.58 & 9.31 & 0.98 & 9.8 \\
\hline Demeron & 1.99 & 1.15 & 0.28 & 1.15 & 0.14 & 35.68 & 0.88 & 1.95 & 1.90 & 0.50 & 0.95 & 0.93 & 0.79 & 0.47 & 0.27 & 0.57 & 0.13 & 7.60 & 0.61 & 3.81 \\
\hline Kabres & 1.30 & 1.16 & 0.10 & 0.59 & 0.07 & 1.13 & 0.73 & 0.04 & 2.1 & 0.79 & 1.61 & 0.77 & 0.63 & 0.59 & 0.25 & 0.78 & 0.19 & 4.49 & 0.95 & 3.8 \\
\hline Kalegron & 2.5 & 1.51 & 1.49 & 1.17 & 0.59 & 3.92 & 0.61 & 0.26 & 1.11 & 0.74 & 0.44 & 0.76 & 0.69 & 0.30 & 0.48 & 0.72 & 0.19 & 8.20 & 0.93 & 3.28 \\
\hline Alsesten & 1.48 & 0.61 & 0.69 & 1.14 & 0.46 & 0.039 & 1.01 & 0.013 & 0.69 & 1.3 & 0.46 & 22.2 & 0.16 & 15.05 & 0.77 & 0.78 & 0.52 & 44.30 & 0.14 & 29.9 \\
\hline Match & 6.73 & 0.79 & 0.03 & 0.86 & 0.004 & 0.0088 & 0.68 & 0.067 & 0.32 & 0.54 & 0.21 & 1.29 & 0.83 & 2.84 & 0.30 & 0.88 & \begin{tabular}{|l|l|}
0.044 \\
\end{tabular} & 9.56 & 0.76 & 1.42 \\
\hline Demefron & 1.68 & 0.91 & 1.52 & 1.23 & 0.90 & 70.56 & 0.91 & 42.00 & 8.73 & 0.40 & 3.41 & 19.61 & 0.61 & 2.84 & 3.33 & 0.99 & 1.98 & 15.69 & 0.73 & 2.34 \\
\hline
\end{tabular}

\section{REFERENCES}

Abbott, W.S. (1925). A method of computing the effectiveness of an insecticide. Journal of Economic Entomology.18: 265-267.

Abdel-Aal AE. Effect of some insect growth regulators on certain biological, biochemical and histopathological aspects of the cotton leafworm, Spodoptera littoralis (Boisd.) (Unpublished). Ph.D. Thesis, Fac. of Sci., Cairo Univ., Egypt, 119.

Abdel-Hay, N. S.; M. Singab; Y.F. Ghoneim and Mona.K. El-Hadek (2014). Resistance levels of some different field strains of the cotton leafworm, Spodoptera littoralis (Boisd.) against certain conventional insecticides and IGR's. J. Plant Prot. and Path., Mansoura Univ., Vol. 5 (2): 299 - 305, 2014

Al-Otaibi, S. A. (2013). Mortality Responses of Spodoptera litura Following Feeding on BT- Sprayed Plants. Journal of Basic \& Applied Sciences, 9, 195-215.

Farag AM. (2001) Biochemical studies on the effect of some insect growth regulators on the cotton leafwarm. Unpublished M. Sc. Thesis, Fac. Of Agric. Cairo Univ.Egypt.

Finney, D.J., (1971). Probit Analysis. Cambridge University Press, Cambridge England.

El-Helaly A.A., HM El - bendary (2015) Field study to evaluate the joint action of certain insecticides, IGR's and baculoviruses against Spodoptera littoralis (Bosid.) Journal of Entomology and Zoology Studies. 3(6): 289-29.

Hafez, S. Sh .M. A. EL- Malla, Reham E. Ali, and Mona K. El-Hadek (2018 ) Resistance Monitoring in Cotton Leaf worm Spodoptera littoralis to Certain Bioinsecticides during Ten Cotton Seasons in Eight Governorates on Egypt. J. Biol. Chem. Research 35 (2) 590-594.

Kandil, M. A.; Abdel-Aziz, N.F. and Sammour, E.A. (2003). Comparative toxicity of chlorofluazron and leufenur on against cotton leaf worm, Spodoptera littoralis (Boisd). Egyp. J. Agric. Res. NRC, 2 :645-661

Seth RK, Kaur JJ, Rad DK, Reynolds SE. (2004) Effect of larval

exposure to sublethal concentrations of the ecdysteroid agonists RH-5849 and Tebufenozide (RH-5992) on male reproductive physiology in Spodoptera litura. J Insect Physiol. 50(6):505-517.

Singab, M; A.S. El-Hefny and M.K. Elhadek (2014) resistance ratio assessment to several bioinsecticides in cotton leafworm, Spodoptera littoralis at different Governorates in Egypt J. plant prot. And path., Mansoura univ., vol. 5 (5): 605-611. 